\title{
Determining African Generation Y Students' Likelihood of Engaging in Pro-environmental Purchasing Behaviour
}

C Synodinos

\author{
North-West University, Vaal Triangle Campus \\ synodinoscosta@gmail.com
}

\section{AL Bevan-Dye PhD.}

North-West University, Vaal Triangle Campus

Ayesha.Bevandye@nwu.ac.za

\section{Doi:10.5901/mjss.2014.v5n21p101}

\begin{abstract}
The continuous growth of the world's population has emphasised the need for pro-environmental behaviour. As the condition of the environment continues to deteriorate, concerns to preserve the environment have begun to increase dramatically. While much research has been conducted on the environmentally-conscious consumer, the results pertaining to pro-environmental purchase behaviour are mixed. Ajzen's Theory of Planned Behaviour model has been an incremental tool in the description of past behaviour patterns in previous studies and recently has been utilised in various environmental behaviour studies around the world. The prediction of pro-environmental behaviour remains an essential tool in the fight towards sustainability, and also offers organisations a possible means of creating a competitive advantage in the process. Therefore, the purpose of this study was to identify any relationships between the variates formed by African Generation Y students' perception and assessment of their beliefs concerning pro-environmental behaviour and their likelihood to engage in pro-environmental purchase behaviour in the South African context. The study followed a cross-sectional descriptive research design that utilised a sample questionnaire to gather data from a convenience sample of 500 students registered at the campuses of four South African higher education institutions in the Gauteng province. The data was analysed using principle component analysis and canonical correlation. This study found that environmental attitudes, subjective norms and perceived behavioural control have a positive direct relationship with African Generation Y students' likelihood of engaging in pro-environmental purchasing behaviour.
\end{abstract}

Keywords: Green marketing; Theory of Planned Behaviour; pro-environmental purchase behaviour; Generation Y; South Africa

\section{Introduction}

The continuous growth of the world's population has emphasised the need for pro-environmental behaviour. As the condition of the environment continues to deteriorate, concerns for the preservation of the environment have begun to increase dramatically (Han, Hsu, \& Sheu, 2010; Chan, 1998). Despite the urgency of the problem, environmental organisations often struggle to lobby active environmental support. A possible barrier may be the ambivalent feelings consumers often have regarding the difference that they can personally make to alleviate the problem (Fielding, McDonald, \& Louis, 2008). Even so, there are many examples through history where consumers have risen up against governments and multi-national corporations in a bid to halt plans that would have destroyed or harmed the environment (see Chen \& Chang, 2012 p.2; Ali, Khan, \& Ahmed, 2011 p.217; Han et al., 2010 p.325; Fielding et al., 2008 p.318). Consequently, marketers have recognised this 'environmental awareness' amongst consumers and are now attempting to capture this newly developed market segment. In doing so marketers are trying predict consumer's environmental behaviours and apply the appropriate marketing strategies (Chen \& Chang, 2012; Ali et al., 2011; Rahbar \& Wahid, 2011).

The Generation Y cohort (individuals born between 1986 and 2014) (Eastman \& Liu, 2012; Markert, 2004) symbolise the future of the environment and environmentalism, which makes this generation a critical component in the success of the green revolution (Lee, 2009). Representing 83 percent of the South African Generation Y cohort, the African segment (hereafter referred to as African Generation $Y$ ) offers lucrative opportunities for marketers due to the magnitude of their size (Statistics South Africa, 2013).

Even though research into the characteristics of the Generation $Y$ cohort is gaining in momentum, published 
literature pertaining to the cohort's environmental behaviour patterns remain lacking, particularly in the South African context and relating to members of the country's African Generation $Y$ cohort. This article aims to address this gap in the literature by making use of Ajzen's Theory of Planned Behaviour in order to predict African Generation Y students' likelihood of engaging in pro-environmental purchase behaviour. The focus on students was deliberate and based on the assumption that a tertiary qualification is often associated with a higher earning potential and an elevated social standings within a community. The combination of these two attributes vastly improves this cohort's opinion leadership abilities amongst the wider African Generation Y target market (Bevan-Dye, 2013).

\section{Environmental Attitudes and Behaviours}

Environmental attitudes are an interesting yet perplexing phenomenon in terms of environmental behaviour. Whilst many studies have found that globally consumers tend to have a positive attitude towards pro-environmental efforts and a heightened concern for the environment (Kalafatis, Pollard, East, \& Tsogas, 1999; Crane, 2000; Laroche, Bergeron, \& Barbaro-Forleo, 2001; Peattie, 2001; Gupta \& Ogden, 2009; Ali et al., 2011; Chang, 2011; Rahbar \& Wahid, 2011; Sodhi, 2011), actual pro-environmental purchase behaviour remains lacking. This is reflected in the studies conducted by Ali et al. (2011), Chang, (2011), Rahbar and Wahid (2011) and Peattie (2001), who found that consumers were positively inclined towards the environment and were environmentally concerned but that this concern did not translate into any actual pro-environmental purchase behaviour. In contrast, studies by Sodhi (2011), Gupta and Ogden (2009), Laroche et al. (2001), Crane (2000) and Kalafatis et al. (1999) indicate that consumers are not only willing to purchase green products but are even willing to pay higher prices for green products in order to conserve the environment. Possible reasons for these contradictory views may include consumers' differing perceptions concerning green products, green washing and/or their ability to influence the environment.

In order to understand environmentally responsible behaviour, it is necessary to understand the influencing factors that determine pro-environmental behaviour. The Theory of Planned Behaviour is a commonly used theoretical model that attempts to predict behavioural patterns of consumers by examining the influencing factors that determine behavioural intentions.

\section{Theory of Planned Behaviour}

The Theory of Planned Behaviour (TPB), which is an extension of Ajzen and Fishbein's Theory of Reasoned Action (Ajzen, 1991), not only aims to predict specific behaviour patterns from attitudes but also attempts to determine the interlinking process between the two variables (Oreg \& Katz-Gerro, 2006). The TPB has demonstrated its use over a wide variety of subjects such as sexual behaviours (Albarracín, Johnson, Fishbein, \& Muellerleile, 2001), social media usage (Al-Debei, Al-Lozi, \& Papazafeiropoulou, 2013), educational behaviour (Zhong, 2013), health-related practices (Vissman, Hergenrather, Rojas, Langdon, Wilkin, \& Rhodes, 2011), driving behaviours (Forward, 2009), tourism (Quintal, Lee, \& Soutar, 2010) and, more recently, environmental behaviours (e.g. Chan \& Bishop, 2013; Kim, Njite, \& Hancera, 2013; Greaves, Zibarras, \& Stride, 2013; Fielding et al., 2008; Oreg \& Katz-Gerro, 2006).

The TPB suggests that behaviour patterns are for the most part determined by intentions, which, in turn, are determined by three predicting variables namely, attitudes, subjective norms and perceived behaviour controls (Oreg \& Kats-Gerro, 2006; Albarracín et al., 2001; Ajzen, 1991). An attitude refers to the extent to which a person displays a favourable or unfavourable assessment of the performed behaviour. Subjective norms include the social pressures experienced from relevant others or from the external environment to perform a certain behaviour. Perceived behaviour control relates to the difficulty or ease individuals perceive performing the actual behaviour (Al-Debei et al., 2013; Forward, 2009; Fielding et al., 2008). Ajzen (1991) cautions for the TPB to be accurate, the measures of intentions (attitude, subjective norm and perceived behaviour control) must correspond or be compatible with the desired predicted behaviour. Therefore, for this particular study, environmental constructs were chosen to represent the TPB.

\section{Generation $Y$}

The future of environmental protection lies in the hands of today's youth (Ottman, 2011; Lee, 2009). Classified as the Generation Y cohort, individuals born between 1986 and 2005 (Markert, 2004; Eastman \& Liu, 2012), the youth are deemed as the green future. In 2013, this Generation ranges from the age of nine to 28 and accounted for approximately 38 percent of South Africa's 52982000 population. In terms of race, approximately 83 percent of the Generation Y cohort in South Africa fell under the African Generation Y cohort classification and collectively made up 32 percent of South 
Africa's total population (Statistics South Africa, 2013).

Generation Y individuals led on by their Baby Boomer or Generation X parents are portraying a distinctive positive shift in their green attitudes and behaviours, even assuming leadership roles in the sustainable market place (Rogers, 2013). The result of being born into such a media saturated world, this generation has been continuously flooded with news of world hunger, natural disasters and the ever present threat of climate change and global warming (Shaw \& Fairhurst, 2008). What gives the Generation $Y$ cohort an advantage over their predecessors is the fact that they have virtual social networking (MXIT, Facebook, Instagram), virtual social reporting (Twitter) and virtual social media (Youtube), at their fingertips to gain information and broadcast their opinions on environmental matters to potentially millions of people around the globe in an instant (Ottman, 2011).

There is evidence that Generation $Y$ individuals prefer to support or lobby organisations that contribute to society in a sustainable manner by helping communities, people and the environment (Barton, Fromm, \& Egan, 2012; Smith, 2012). Since members of this generation known to be heavy users of the Internet (Schwalbe, 2009; Barton et al., 2012), mobile telephones (Kumar \& Lim, 2008; Schwalbe, 2009) and virtual social networking sites (Nicholas, Rowlands, Clark, \& Williams, 2011; Barton et al., 2012) green marketers should utilise these media platforms to reach out to this specific cohort (Lee, 2009). However, caution should be taken as this generational cohort is quick to criticise and spot bogus green marketing practices (Ottman, 2011).

Given that the Generation $Y$ cohort has had greater access to information than any former generation, they should be aware of and knowledgeable about the threat that human action poses to the environment (Lee, 2009; Ottman, 2011). It is this Generations votes, actions and how they carry on the message to future generations that will ultimately dictate the next half-century or more of the green movement (Lee, 2009). Research indicates that Generation $Y$ individuals actively encourage others to support cause campaigns (Barton et al., 2012). With regards to South Africa, the African Generation Y cohort represents an important target market for green marketers and, as indicated by Barton et al. (2012), getting this generational cohort to engage with brands, including green brands, involves designing marketing messages that are applicable to and mindful of them.

\section{Research Methodology}

\subsection{Sampling method}

The target population of this study was African Generation Y students currently enrolled at South African public higher education institutions (HEIs) in 2014 in the age range of 18 to 24. The sampling frame consisted of the 25 public registered HEls within Southern Africa by the Higher education in South Africa (HESA, 2014). A judgement sample of four campuses from four HEls within the Gauteng province was taken from the initial list of 25 registered institutions - two of which were city-based universities and two that were country based universities. Amongst the chosen universities, two comprised traditional universities, one a comprehensive university and one a university of technology. The study utilised a non-probability convenience sample of 500 full-time African Generation Y students spread across the four campuses. Lectures at each of the four campuses were contacted and asked if they would allow the questionnaire to be distributed to their students during or after their lecture. The questionnaire was then distributed to those lecturers' students who had granted permission by fieldworkers. It was also emphasised that participation in the study was purely on a voluntary basis.

\subsection{Research instrument}

This study made use of a self-administered, structured questionnaire. African Generation Y students' environmental attitudes were measured using the inward environmental attitudinal scale (four items), validated by Leonidou, Leonidou, \& Kvasova (2010). Subjective norms and perceived behaviour control were measured using the three- and five-item validated scales of Fielding et al. (2008) and Kim and Choi (2005). Green purchase intentions were measured using Mostafa's (2007) three item scale and green purchase behaviour was measured using the four item scale validated by Lee (2008). All scaled responses were recorded on a six-point Likert scale, ranging from strongly disagree (1) to strongly agree (6).

In order to assess the reliability of the measurement instrument the questionnaire was piloted on a convenience sample of 50 students at a South African HEI campus that did not form part of the sampling frame. The Cronbach alpha values of the pilot study all exceeded the acceptable level of being above 0.60 (Malhotra, 2010) and ranged from 0.67 to 0.76 , thereby suggesting acceptable reliability. 


\section{Results}

\subsection{Sample description}

From the initial 500 questionnaires distributed, 332 viable questionnaires were returned, thereby yielding a response rate of 66 percent. The majority of the participants were in the 19 to 21 year old range (60\%). The year of study category was dominated by first-year students, followed by second-year students and the remainder made up third-year and postgraduate students. There were more female participants than males. The sample comprised more participants from country-based campuses (56\%) than from city-based campuses.

Table 1. Sample description

\begin{tabular}{cccclclc}
\hline Age & Percent (\%) & Gender & Percent (\%) & Year of study & Percent (\%) & Institution & Percent (\%) \\
\hline 18 & 13 & Male & 47 & First year & 42 & University A: & \\
19 & 17 & Female & 52 & Second year & 26 & Country based & 24 \\
20 & 19 & & & Third year & 25 & University B: & \\
21 & 24 & & & Postgraduate & 8 & Country based & 32 \\
22 & 15 & & & & & University C: & \\
23 & 9 & & & & & City based & 19 \\
24 & 4 & & & & & University D: & \\
& & & & & & & \\
\hline
\end{tabular}

\subsection{Confirmatory factor analysis}

A confirmatory factor analysis was conducted to assess the factor structure of the TPB model in the South African context. First, the Kaiser-Meyer-Olkin (KMO) measure of sampling adequacy and the Bartlett Test of Sphericity were examined. A KMO value above 0.6 and a significant Bartlett's Test of Sphericity value are recommended (Pallant, 2010). The results of these two tests yielded a KMO value of 0.899 and a significant Bartlett Test of Sphericity value (chi-square $=2542.989(\mathrm{df}=171),(\mathrm{p}=0.000<0.05))$. Once the sampling adequacy had been established, a principle component analysis using varimax rotation was undertaken. Table 2 reports on the factor loadings in the rotated matrix.

Table 2. Principle component factor analysis with varimax rotation

\begin{tabular}{|c|c|c|c|c|c|c|}
\hline \multirow{2}{*}{ Perception items } & \multicolumn{5}{|c|}{ Factor loadings } & \multirow[t]{2}{*}{ Communalities } \\
\hline & 1 & 2 & 3 & 4 & 5 & \\
\hline \multicolumn{7}{|l|}{ Environmental attitude } \\
\hline I am concerned about the environment. & & & & & .778 & .648 \\
\hline I would be willing to reduce my consumption to help protect the environment. & & & & & .722 & .636 \\
\hline I would donate part of my own money to help protect wild animals. & & & & & .464 & .484 \\
\hline I have asked my family to recycle some of the things we use. & & & & & .450 & .545 \\
\hline \multicolumn{7}{|l|}{ Subjective norms } \\
\hline People who are important to me behave in an environmentally friendly way. & & & & .814 & & .745 \\
\hline $\begin{array}{l}\text { People who are important to me would approve of me behaving in an environmentally } \\
\text { friendly way. }\end{array}$ & & & & .636 & & .582 \\
\hline $\begin{array}{l}\text { People who are important to me encourage me to behave in an environmentally friendly } \\
\text { way. }\end{array}$ & & & & .777 & & .684 \\
\hline
\end{tabular}

\section{Perceived behavioural control}

By signing a petition that promotes environmental protection, every person can have a positive effect on society.

\section{Purchase intentions}

Over the next month, I will consider buying products because they are less polluting. 


\section{Purchase behaviour}

When I want to buy a product, I look at the ingredients label to see if it contains things

that are environmentally-damaging.

.650

.821

.644

.593
.647

.735

.658

.638

As presented in Table 2, five factors emerged that explained 64 percent of the total variance. All variables loaded as expected and all had significant loadings of above 0.40 . Given that the number of observations exceeded 300 , these significant loadings suggest convergent validity. In addition, all of the communalities were above 0.40 , with the majority being above 0.50 , thereby suggesting that a large amount of the variance in an item has been extracted by the factor solution (Hair, Black, Babin, \& Anderson, 2010). The principle component analysis was then repeated using the nonorthogonal direct oblimin rotation in order to generate a component correlation matrix. The interpretation remained the same as with the varimax rotation. None of the correlation coefficients in the component correlation matrix exceeded 0.70 , with the highest value being 0.361 , thereby suggesting discriminate validity (Fields, 2009).

\subsection{Descriptive statistics and reliability coefficients}

The descriptive statistics and reliability coefficients of these five factors are reported in Table 3.

Table 3. Descriptive statistics and reliability coefficients

\begin{tabular}{lccc}
\hline Factors & Mean & Standard deviation & Cronbach alpha \\
\hline Environmental attitude & 4.4375 & .86780 & .662 \\
Subjective norms & 4.2631 & 1.07572 & .757 \\
Perceived behavioural control & 4.8476 & .77609 & .794 \\
Purchase intentions & 4.4016 & 1.03092 & .841 \\
Purchase behaviour & 3.9925 & 1.13710 & .817 \\
\hline
\end{tabular}

As indicated in Table 2, all means exceeded 3, which suggest that African Generation $Y$ students have a positive perception of pro-environmental behaviour and are likely to engage in pro-environmental purchase behaviour. Whilst the Cronbach alpha coefficients exceeded the recommended level of 0.70 (Pallant, 2010) for the majority of the factors, the alpha value was slightly low for the environmental attitude factor, but still above the acceptable level of 0.60 (Malhotra, 2010).

\subsection{Canonical correlation}

Owing to the study including a multivariate method in the data analysis, a tolerance test was run to check for multicollinearity (Hair et al., 2010). The tolerance values were all high, ranging from 0.70 to 0.73 , thereby indicating only a small and therefore negligible degree of multicollinearity.

Canonical correlation was then undertaken to identify any relationships between the variates formed by African Generation Y students' perception and assessment of their beliefs concerning pro-environmental behaviour and their likelihood to engage in pro-environmental purchase behaviour. The set of dependent variables was defined as purchase intentions and purchase behaviour, and the set of independent variables as environmental attitudes, subjective norms and perceived behavioural control.

Given that the smallest set of variables contained only two indicators, only two canonical functions were derived. These two functions, together with the measures of the overall model fit are reported on in Table 4. 
Table 4. Measures of overall model fit

\begin{tabular}{|c|c|c|c|c|}
\hline Canonical function & Canonical correlation & Canonical $\mathbf{R}^{2}$ & F statistics & Probability \\
\hline 1 & 0.640 & 0.409 & 36.83 & 0.000 \\
\hline 2 & 0.233 & 0.054 & 9.42 & 0.000 \\
\hline \multicolumn{5}{|c|}{ Multivariate tests of significance } \\
\hline Statistic & Value & \multicolumn{2}{|c|}{ Approximate F statistic } & Probability \\
\hline Wilk's lambada & 0.559 & \multicolumn{2}{|c|}{36.828} & 0.000 \\
\hline Pilia's trace & 0.464 & \multicolumn{2}{|c|}{32.984} & 0.000 \\
\hline Hotelling's trace & 0.750 & \multirow{2}{*}{\multicolumn{2}{|c|}{40.757}} & 0.000 \\
\hline Roy's gcr & 0.409 & & & \\
\hline
\end{tabular}

As shown in Table 4, the analysis resulted in two functions with squared canonical correlations of 0.409 and 0.054 for each successive function. Wilk's lambada, Pilia's trace, Hotelling's trace and Roy's greater characteristic root (gcr) indicate that, collectively, the overall model across all functions is statistically significant; that is, there is a relationship between the variable sets.

Despite both Function 1 and Function 2 being statistically significant, only the first function was considered for further analysis given that it explains 40 percent of the amount of shared variance between the two sets of canonical variate scores, whilst the second function explains a negligible 5 percent, which is not practically significant.

A redundancy analysis for the independent and dependent variables of the first functions was conducted and the results are reported in Table 5.

Table 5. Redundancy analysis for the first canonical function

\begin{tabular}{cccccc}
\hline \multicolumn{7}{c}{ Standardised variance of the dependent variables explained by } \\
\hline \multicolumn{7}{c}{ Shared variance } & \multicolumn{2}{c}{ Redundancy } \\
\hline Canonical function & Percentage & Cumulative percentage & Canonical $\mathbf{R}^{2}$ & Percentage & Cumulative percentage \\
\hline 1 & 0.804 & 0.804 & .409 & 0.329 & 0.329 \\
\hline \multicolumn{7}{c}{ Standardised variance of the independent variables explained by } \\
\hline \multicolumn{7}{c}{ Shared variance } & \multicolumn{2}{c}{ Redundancy } \\
\hline Canonical function & Percentage & Cumulative percentage & Canonical $\mathbf{R}^{2}$ & Percentage & Cumulative percentage \\
\hline 1 & 0.629 & 0.629 & 0.409 & 0.257 & 0.257 \\
\hline
\end{tabular}

Table 5 illustrates that the redundancy for the dependent variate $(0.329)$ is higher than for the independent variate (0.257). Therefore, the independent variate is able to predict 32.9 percent of the variance in the dependent variate.

Having established that the canonical relationship is statistically significant and redundancy index acceptable, the next step involved analysing the canonical weights, canonical loadings and canonical cross-loadings, which are reported in Table 6.

Table 6. Canonical weights, loadings and cross-loadings

\begin{tabular}{lccc}
\hline & Canonical weights & Canonical loadings & Canonical cross-loadings \\
\hline Independent variables & & & \\
Environmental attitude & 0.517 & 0.847 & 0.542 \\
Subjective norms & 0.478 & 0.817 & 0.522 \\
Perceived behavioural control & 0.243 & 0.709 & 0.454 \\
Dependent variables & & & 0.565 \\
Purchase intentions & 0.522 & 0.883 & 0.582 \\
Purchase behaviour & 0.592 & 0.910 & \\
\hline
\end{tabular}

While Table 6 reports the canonical weights, loadings and cross-loadings, Hair et al. (2010) advise that it is preferable to analyse the canonical cross-loadings when interpreting the nature of canonical relationships. In terms of the canonical cross-loadings of the dependent variables, 32 percent of the variance in purchase intentions and 34 percent of the variance in purchase behaviour is explained by the first canonical function. An examination of the independent variables' cross-loadings reveals that environmental attitude has the highest correlation with the dependent variate, followed by subjective norms and perceived behavioural control. Therefore, environmental attitude, subjective norms and, to a lesser 
extent, perceived behavioural control have a direct positive relationship with African Generation Y students' likelihood of engaging in pro-environmental purchasing behaviour and are predictors of this outcome dimension.

\section{Discussion}

As natural resources continue to deplete drastically, South Africans (along with the rest of the world) need to take action to ensure the survival of the environment for future generations to come. These environmental issues have crossed over into the marketing arena where the future of the 'green revolution' is highly dependent on the purchasing behaviour of the youth. In the case of South Africa, the Generation Y cohort, especially the vastly sized African segment of this cohort is pivotal to the country's environmental sustainability.

As it stands, environmental depletion exceeds the rate that the environment can replenish itself; hence, the need for pro-environmental purchase behaviour. Whether it is changing energy-saving light bulbs, recycling, reusing plastics or purchasing environmentally-friendly products, the environment is dependent on individuals behaving in a proenvironmental manner for its survival. Marketers and environmentalists need to promote environmentally-friendly products and governments and large corporations need to take action on a green front.

A fundamental issue in marketing is understanding a market segment's attitudes about the act of purchasing a particular product category. This study utilised the well-known, established and validated TPB model in the South African context to determine African Generation Y students' likelihood of engaging in pro-environmental purchasing behaviour. The factor structure that emerged from the confirmatory factor analysis was in line with that of the TPB model. The descriptive statistics suggest that African Generation $Y$ students have a positive attitude towards pro-environmental behaviour and pro-environmental purchase behaviour

Consistent with the TPB, canonical cross-loadings indicate that environmental attitudes, subjective norms and perceived behavioural control are significant positive predictors of African Generation Y students' likelihood of engaging in pro-environmental purchasing behaviour. Perceived behavioural control had the lowest correlation with the dependent variate, whilst environmental attitude and subjective norms had the highest correlation. These findings are similar to those of Kim et al. (2013), Fielding et al. (2008) and, Kelly and Breinlinger (1995). This suggests that marketing campaigns designed to encourage pro-environmental purchasing behaviour amongst members of the African Generation Y cohort should focus on creating environmental awareness and raising environmental concerns. Pro-environmental behaviour as a subjective norm may be stimulated using green advertisements depicting African Generation $Y$ individuals socially rejecting individuals engaging in non-environmentally friendly behaviour. Perceived behavioural control may be triggered by showing how one person's efforts contribute to alleviating environmental problems.

\section{Limitations and Implications for Future Research}

The limitations pertaining to this study need to be considered in interpreting the findings. The first limitation is that a nonprobability sampling method was used to capture the required data.

A second limitation is that this study only offers a single snap shot in time, as a cross-sectional design was employed to capture the data. Consumers' attitudes and inclination towards pro-environmental purchasing behaviour may change over time. For example, unethical green marketing practices may produce consumer myopia towards green marketing practices in general. Even a popular movie or speech by a politician or a celebrity debunking the seriousness of environmental problems may negatively impact on consumers' pro-environmental attitudes and behaviour.

In addition, this study focused on consumers' theoretical intentions and future behavioural patterns towards consuming green products and did not measure the extent of their actual green product purchases. As such, future research relating to African Generation $Y$ students likelihood of engaging in pro-environmental purchasing behaviour together with the extent of their green product purchases is advised.

\section{Conclusion}

Global warming and the rapid depletion of the earth's natural resources represent an omnipresent threat. In South Africa, the future of the country's environment is in the hands of the youth, particularly in the hands of the significantly sized African Generation $Y$ cohort. The willingness of members of this cohort to engage in pro-environmental behaviour, including pro-environmental purchasing behaviour will dictate the state of the South African environment for future generations. 


\section{References}

Ajzen, I. (1991). The Theory of Planned Behavior. Organizational Behaviour and Human Decision Processes, 50(2), $179-211$.

Albarracín, D., Johnson, B. T., Fishbein, M., \& Muellerleile, P. A. (2001). Theories of Reasoned Action and Planned Behavior as Models of Condom Use: A Meta-Analysis. Psychological Bulletin, 127(1), 142-161.

Al-Debei, M.M., Al-Lozi, E. \& Papazafeiropoulou, A. (2013). Why people keep coming back to Facebook: explaining and predicting continuance participation from an extended theory of planned behaviour perspective. Decision Support Systems, 55(1), 43-54.

Ali, A., Khan, A.A. \& Ahmed, I. (2011). Determinants of Pakistani consumers' green purchase behavior: some insights from a developing country. International Journal of Business and Social Science, 2(3), 217-226.

Barton, C., Fromm, J. \& Egan, C. (2012). The Millennial consumer: debunking stereotypes. The Boston Consulting Group, 16 April. https://www.bcgperspectives.com/content/articles/consumer_insight_marketing_millennial_consumer/ (5 October 2012).

Bevan-Dye, AL. (2013). Black Generation Y Students' Attitudes towards Web Advertising Value. Mediterranean Journal of Social Sciences, 4(2), 155-164.

Chan, K. (1998). Mass communication and proenvironmental behaviour: waste recycling in Hong Kong. Journal of Environmental Management, 52(1), 317-325.

Chan, L. \& Bishop, B. (2013). A moral basis for recycling: Extending the theory of planned behaviour. Journal of Environmental Psychology, 36(1), 96-102.

Chang, C. (2011). Feeling ambivalent about going green: Implications for green advertising processing. Journal of Green Advertising, 40(4), 19-31.

Chen, Y.S. \& Chang, C.H. (2012). Enhance green purchase intentions: the roles of green perceived value, green perceived risk, and green trust. Management Decision, 50(3), 1-43

Crane, A. (2000). Facing the backlash: green marketing and strategic reorientation in the 1990s. Journal of Strategic Marketing, 8(1), 277-296.

Eastman, J.K. \& Liu, J. (2012). The impact of generational cohorts on status consumption: an exploratory look at generational cohort and demographics on status consumption. Journal of Consumer Marketing, 29(2), 93-102.

Fielding, K., McDonald, R. \& Louis, W. R. (2008). Theory of planned behaviour, identity and intentions to engage in environmental activism. Journal of Environmental Psychology 28(4), 318-326.

Fields, A. (2009). Discovering statistics using SPSS (3rd ed.). Thousand Oaks, C.A.: Sage.

Forward, E. S. (2009). The theory of planned behaviour: the role of descriptive norms and past behaviour in the prediction of drivers' intentions to violate. Transportation Research, 12(3), 198-20.

Greaves, M., Zibarras, L.D. \& Stride, C. (2013). Using the theory of planned behavior to explore environmental behavioural intentions in the workplace. Journal of Environmental Psychology, 34(1), 109-120.

Gupta, S. \& Ogden. (2009). To buy or not to buy? A social dilemma perspective on green buying. Journal of Consumer Marketing, 26(6), 376-391.

Hair, J.F., Black, W.C., Babin, B.J. \& Anderson, R.E. (2010). Multivariate data analysis: a global perspective (7th ed.). Upper Saddle River, N.J.: Pearson.

Han, H, Hsu, L. \& Sheu, C. (2010). Application of the Theory of Planned Behavior to green hotel choice: Testing the effect of environmental friendly activities. Tourism Management, 31(1), 325-334.

Higher Education of South Africa. (2014). http://www.hesa.org.za/sa-universities (14 February 2014).

Kalafatis, P.S., Pollard, M., East, R. \& Tsogas, H.M. (1999). Green marketing and Ajzen's theory of planned behavior: a cross-market examination. Journal of Consumer Marketing, 16(5), 441-460.

Kelly, C. \& Breinlinger, S. (1995). Attitudes, intentions and behaviour: A study of women's participation in collective action. Journal of Applied Social Psychology, 25(16), 1430-1445.

Kim, Y. J., Njite, D. \& Hancera, M. (2013). Anticipated emotion in consumers' intentions to select eco-friendly restaurants: Augmenting the theory of planned behaviour. International Journal of Hospitality Management, 34(1), 255-262.

Kim, Y. \& Choi, S. M. (2005). Antecedents of green purchase behavior: an examination of collectivism, environmental concern, and PCE. Advances in Consumer Research, 32 (1), 592-599.

Kumar, A. \& Lim, H. (2008). Age differences in mobile service perceptions: comparison of Generation Y and baby boomers. Journal of Services Marketing, 22(7), 568-577.

Laroche, M., Bergeron, J. \& Barbaro-Forleo, G. (2001). Targeting consumers who are willing to pay more for environmentally friendly products. Journal of Consumer Marketing, 18(6), 503-520.

Lee, K. (2008). Opportunities for green marketing: young consumers. Marketing Intelligence \& Planning, 26(6), 573-586.

Lee, K. (2009). Gender differences in Hong Kong adolesant consumer's green purchasing behaviour. Journal of Consumer Marketing, 26(2), 87-96

Leonidou, C.L., Leonidou, N.C. \& Kvasova, O. (2010). Antecedents and outcomes of consumer environmentally friendly attitudes and behaviour. Journal of Marketing Management, 26(13), 1319-1344.

Malhotra, K. N. (2010). Marketing research: an applied orientation. (6 $6^{\text {th }}$ ed). Upper Saddle River, N.J: Pearson Education.

Markert, J. (2004). Demographics of age: generational and cohort confusion. Journal of Current Issues and Research in Advertising, 26 (2), 11-25.

Mostafa, M. M. (2007). A hierarchical analysis of the green consciousness of the Egyptian consumer. Pschology \& Marketing, 24(5), 
445-473.

Nicholas, D., Rowlands, I., Clark, D. \& Williams, P. (2011). Google generation II: web behaviour experiments with the BBC. Aslib Proceedings: New Information Perspectives, 63(1), 28-45.

Oreg, S. \& Katz-Gerro, T. (2006). Predicting proenvironmental behaviour cross-nationally: Values, the theory of planned behavior, and value-belief-norm theory. Environment and Behavior, 38 (4), 462-483.

Ottman, A. J. (2011). The new rules of green marketing: Strategies, tools, and inspiration for sustainable branding. Sheffield, United Kingdom: Greenleaf Publishing Limited.

Pallant, J. (2010). SPSS survival manual. (4th ed). London: Open University Press.

Peattie, K. (2001). Towards sustainability: The third age of green marketing. Journal of The Marketing Review, 2(2), 129-147.

Quintal, A.V., Lee, A.J. \& Soutar, G.N. (2010). Risk, uncertainty and the theory of planned behavior: A tourism example. Tourism Management, 31(6), 797-805.

Rahbar, E. \& Wahid, N.A. (2011). Investigation of green marketing tools' effect on consumers' purchase behavior. Journal of Business Strategies Series, 12(2), 73-83.

Rogers, G. (2013). The rise of Generation Y in the sustainable marketplace. The guardian, 3Feb. http://www.guardian.co.uk/sustainablebusiness/blog/rise-generation-y-sustainable-marketplace (26 February 2013).

Schwalbe, B.C. (2009). Leveraging the digital media habits of the millenials: Strategies for teaching journalism courses. Journal of Southwestern Mass Communication, 25(1), 53-68.

Shaw, S. \& Fairhurst, D. (2008). Engaging a new generation of graduates. Education + Training, 50(5), 366-378.

Smith, T. K. (2012). Longitudinal study of digital marketing strategies targeting Millennials. Journal of Consumer Marketing, $29(2), 86-92$.

Sodhi, K. (2011). Has marketing come full circle? Demarketing for sustainability. Journal of Business Strategies, 12(4), 177-185.

Statistics South Africa. (2013). Mid-year population estimates: 2011. Key indicators, Statistical release P0302. http://www.statssa.gov.za (17 June 2013).

Vissman, A.T., Hergenrather, K.C., Rojas, G., Langdon, S.E., Wilkin, A.M. \& Rhodes, S. D. (2011). Applying the theory of planned behavior to explore HAART adherence among HIV-positive immigrant Latinos: Elicitation interview results. Patient Education and Counseling, 85(3), 454-460.

Zhong, M. (2013). Understanding Chinese learners' willingness to communicate in a New Zealand ESL classroom: A multiple case study drawing on the theory of planned behaviour. System, 41(3), 740-751. 
